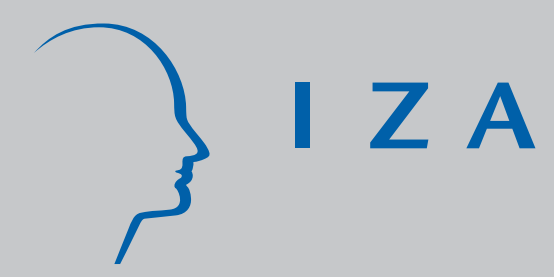

IZA DP No. 3382

Subjective Performance Evaluation and Inequality Aversion

Christian Grund

J udith Przemeck

March 2008 


\title{
Subjective Performance Evaluation and Inequality Aversion
}

\author{
Christian Grund \\ University of Wuerzburg \\ and IZA
}

Judith Przemeck

University of Bonn

\author{
Discussion Paper No. 3382 \\ March 2008
}

\author{
IZA \\ P.O. Box 7240 \\ 53072 Bonn \\ Germany \\ Phone: +49-228-3894-0 \\ Fax: +49-228-3894-180 \\ E-mail: iza@iza.org
}

\begin{abstract}
Any opinions expressed here are those of the author(s) and not those of IZA. Research published in this series may include views on policy, but the institute itself takes no institutional policy positions.

The Institute for the Study of Labor (IZA) in Bonn is a local and virtual international research center and a place of communication between science, politics and business. IZA is an independent nonprofit organization supported by Deutsche Post World Net. The center is associated with the University of Bonn and offers a stimulating research environment through its international network, workshops and conferences, data service, project support, research visits and doctoral program. IZA engages in (i) original and internationally competitive research in all fields of labor economics, (ii) development of policy concepts, and (iii) dissemination of research results and concepts to the interested public.
\end{abstract}

IZA Discussion Papers often represent preliminary work and are circulated to encourage discussion. Citation of such a paper should account for its provisional character. A revised version may be available directly from the author. 
IZA Discussion Paper No. 3382

March 2008

\section{ABSTRACT}

\section{Subjective Performance Evaluation and Inequality Aversion ${ }^{*}$}

Many firms use subjective performance appraisal systems due to lack of objective performance measures. In these cases, supervisors usually have to rate the performance of their subordinates. Using such systems, it is a well established fact that many supervisors tend to assess the employees too good (leniency bias) and that the appraisals hardly vary across employees of a certain supervisor (centrality bias). We explain these two biases in a model with a supervisor, who has preferences for the utility of her inequality averse subordinates, and discuss determinants of the size of the biases. Extensions of the basic model include the role of supervisor's favoritism of one particular agent and the endogenous effort choice of agents. Whether inequality averse agents exert higher efforts then purely selforiented ones, depends on the size of effort costs and inequality aversion.

JEL Classification: M5, D63

Keywords: appraisals, inequality aversion, performance evaluation, centrality bias, leniency bias

Corresponding author:

Christian Grund

Department of Business and Economics

University of Würzburg

Am Sanderring 2

D-97070 Würzburg

Germany

E-mail: christian.grund@uni-wuerzburg.de

* Many thanks to Matthias Kraekel and Norbert Schulz for helpful comments. 


\section{Introduction}

Performance appraisal is one of the most frequently discussed topics of human resource management research. ${ }^{1}$ Systematic performance appraisal systems can be implemented for several purposes including promotion and training decisions, performance based variable pay and personnel planning (Cleveland et al. 1989). In many cases it is not possible to obtain objective performance measures on an individual base. Besides, existing objective measures usually correspond only to part of employees' tasks, which may lead to distorted incentives (Milgrom \& Roberts 1988, Holmström \& Milgrom 1991). Therefore, many firms implement some kind of subjective performance evaluation.

Subjective performance evaluation, however, is also fraught with some problems. One issue is that the accuracy of ratings is not given automatically. If the rater is a residual claimant (i.e. the owner of a firm) and the appraisal affects some kind of variable pay, she may underreport the performance of her subordinates in order to save costs. However, many supervisors are no residual claimants but themselves employed workers in multi layered firms. Therefore, supervisors can also be interpreted as agents with own utility functions, which may deviate from the principal's objectives. In this situation possible rater biases include the centrality bias and the leniency bias. ${ }^{2}$ In many firms the majority of employees get ratings above the average mark. Therefore, the appraisals are by definition skewed to the top end of the scale and supervisors rate some kind of lenient (e.g. Jawahar \& Williams 1997). Besides, several studies find that only a small fraction of possible performance levels is used by the supervisors when evaluating subordinates. They tend to differentiate only slightly between employees (e.g. Murphy \& Cleveland 1991). These biases may not only be inefficient for firms but also lead to the problem that the performance appraisal system is not accepted by several employees as Murphy (1992) observes for the pharma company Merck \& Co, Inc. More than 70 percent of employees are located in only three of 13 performance categories and only about 5 percent have got marks beyond the average one in this case (see Figure 1).

\footnotetext{
${ }^{1}$ Bretz et al. (1992) as well as Levy \& Williams (2004) provide extensive surveys of the literature.

${ }^{2}$ Other biases that are discussed in the literature include the halo, primacy and recency effect (see e.g. Murphy \& Cleveland 1995).
} 
Figure 1: Distribution of subjective performance appraisals at Merck \& Co., Inc.

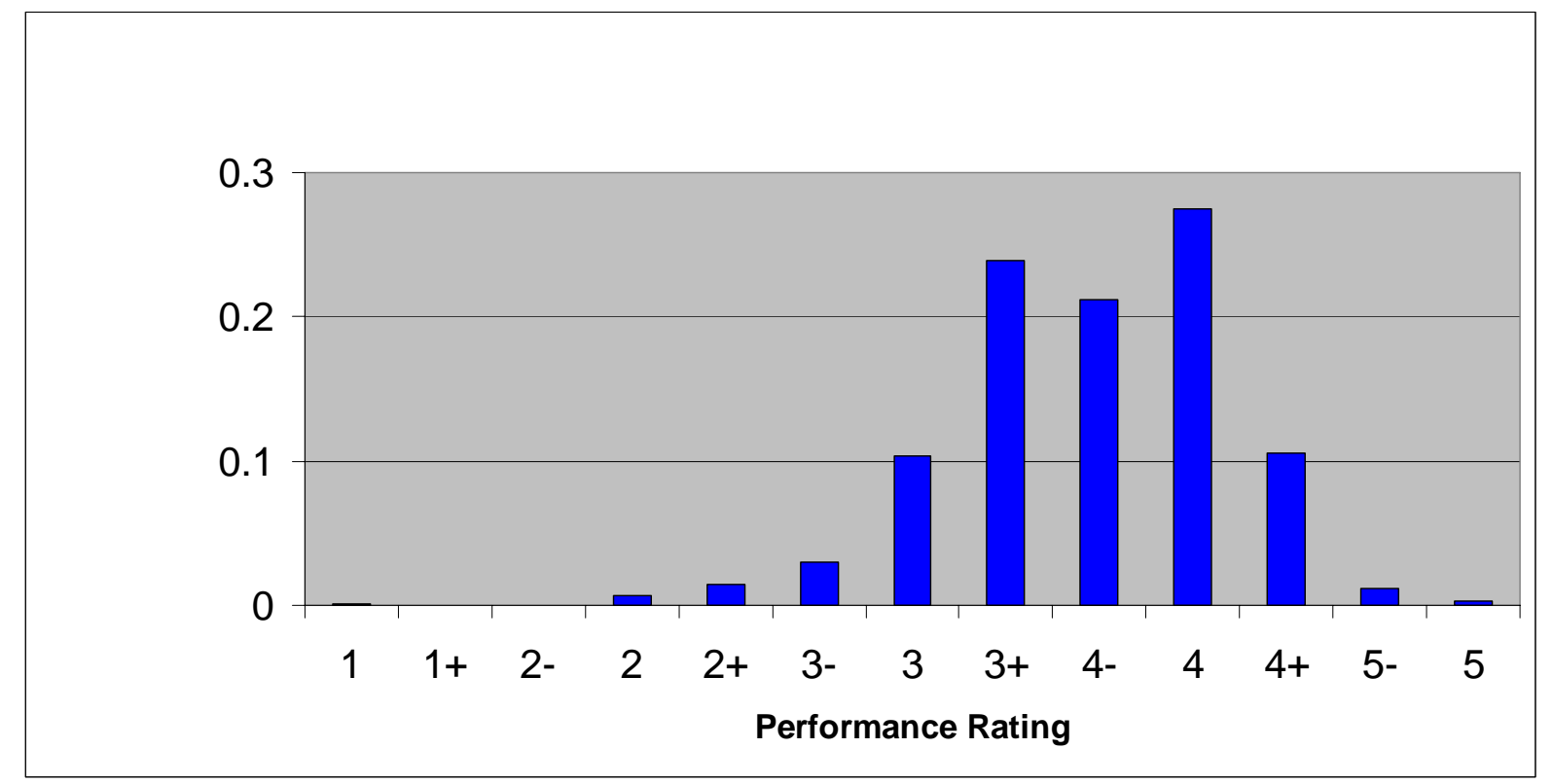

Note: 1 = unacceptable performance, 5 = exceptional performance.

Source: Murphy (1992), p. 40.

Several reasons for these biases are discussed in the empirical literature. If supervisors are not rewarded for accurate ratings, they may have insufficient motivation to invest time in gathering information (Fox et al. 1983). Furthermore, they may also face cognitive limitations and tend to focus on some performance dimensions (Ittner et al. 2003) or arbitrarily favor certain employees e.g. to encourage loyalty or to serve their self-interest (Ferris \& Judge 1991). Besides, supervisors may have a preference for a pleasant relationship with their subordinates (Varma et al. 1996). Negative feedback may lead to undesirable discussions and is therefore avoided if possible. ${ }^{3}$

The contributions of Prendergast and Topel (1996) as well as Prendergast (2002) are two of the few theoretical studies which provide explanations for the leniency bias by assuming that the well-being of subordinates is part of the supervisor's utility function. In Prendergast and Topel (1996) a supervisor can distort her reports but is monitored by the management. Since biased reports lead to inefficient job assignments, management punishes the supervisor if her report deviates from the management's own observation. Similarly, Prendergast (2002) assumes that the supervisor faces some cost when deviating from the truth. Both contributions

\footnotetext{
${ }^{3}$ See also Bol (2005) for a more detailed overview of the literature.
} 
show that favoritism increases with the worker's incentives. ${ }^{4}$ Assessments are distorted upwards the more the supervisor likes a particular agent and downwards the more she dislikes a subordinate.

In this paper we build on this argument and additionally assume that employees are inequality averse to each other. We can simultaneously explain both the leniency bias and the centrality bias within our simple model. If agents are inequality averse, it is obvious that agents profit from distorted ratings to the mean from an ex post perspective. However, it is not obvious how ex ante incentives of different agents are affected assuming that there is uncertainty in the production technology. We show that the effect of distorted ratings on incentives depends on the type of the agent (purely self-interested versus inequality averse). While purely selfinterested agents are not influenced by distorted ratings, the behavior of inequality averse agents changes. If the supervisor distorts reports, there are situations, in which very inequality averse agents exert higher efforts than purely self-interested agents.

It is now more and more accepted that inequality aversion is an important driving force of human behavior in many situations. Based on experiments by e.g. Loewenstein et al. (1989), Fehr and Schmidt (1999) as well as Bolton and Ockenfels (2000) provide suggestions for operationalizations of inequality aversion in economic models. Recent applications of inequality aversion in principal-agent-models include individual (Itoh, 2004, Neilson \& Stowe, 2004, Mayer \& Pfeiffer, 2004, Englmaier \& Wambach, 2005, Demougin et al., 2005) and team based incentive contracts (Itoh 2004, Demougin \& Fluet 2003a, Biel 2004), rankorder tournaments (Demougin \& Fluet 2003b, Grund \& Sliwka 2005) and adverse selection problems (von Siemens 2005, Desiraju \& Sappington 2007). However, inequality aversion has not been applied to performance appraisal issues so far. Simultaneously and independently from this paper Sliwka (2007b) gives another explanation for the centrality bias by incorporating two (not identical) signals of the agents' performances for a supervisor and a principal. The centrality bias is due to the supervisor's inequity aversion and a regression to the mean effect of the supervisor's report, because she wants to avoid own disadvantages from deviating from the principal's signal.

\footnotetext{
${ }^{4}$ Sliwka (2007a) provides a different model on performance appraisal with one loss averse agent and shows in a two period model that the leniency bias becomes more relevant over time. MacLeod (2003) investigates optimal contracts with subjective performance evaluations when the signals of a principal and an agent about the performance of the agent are not correlated. In order to avoid conflicts with the agent the supervisor (who is the principal in this case) compresses the ratings at the top which is similar to the centrality bias.
} 
In the next section we proceed by providing a simple model. A supervisor has to appraise the performance of two employees. Her utility depends on the firm's profit and on the well-being of her inequality averse subordinates. We simultaneously explain both the centrality and leniency bias within this simple model. We also discuss determinants of the degree of both biases and extent the model to a situation with favoritism, when the supervisor has preferences for the well-being of only one subordinate (section 3). Furthermore, agents may anticipate the biased reports of the supervisor and endogenously choose efforts levels. We discuss this case in section 4 and show that efforts with biased reports are higher compared to a situation with unbiased reports if the amount of inequality aversion is rather high. Section 5 concludes.

\section{A simple model}

Suppose that a supervisor $S$ has to assess the performance of two agents $i$ and $j$ ( $i$ and $j=1,2$; $i \neq j$ ) to determine their wages. Her verifiable report for agent $i$ is characterized by the term $r_{i}>0$. We assume that the supervisor is not a residual claimant, but employed in a firm. She observes the true performance $p_{i}>0$ of both agents and then has to state a report $r_{i}$ for each agent. The wage $W_{i}$ of agent $i$ consists of two components. He receives a performance appraisal contingent bonus $b r_{i}(b>0)$ in addition to his fixed wage $w>0$, i.e. $W_{i}=w+b r_{i}$. For simplicity we assume that both agents are equally inequality averse. To model their utilities we use the utility function proposed by Fehr and Schmidt (1999). If the performance appraisal of $i$ is lower than the performance appraisal of $j$, agent $i$ is jealous of $j$. The resulting disutility increases in the difference of the performance ratings $\left(r_{j}-r_{i}\right)$, in the report dependent wage component $b$, and in the degree of disadvantageous inequality aversion $\alpha$. If instead agent $i$ is better assessed, he may feel some kind of compassion or guilt with agent $j$. The extent of such feelings is given by the parameter $\beta$. Thus, the utility function of an agent who is inequality averse is given by

$$
\begin{aligned}
U_{i}\left(r_{i}, r_{j}\right) & =W_{i}-\alpha\left(\max \left\{W_{j}-W_{i}, 0\right\}\right)-\beta\left(\max \left\{W_{i}-W_{j}, 0\right\}\right) \\
& =w+b r_{i}-\alpha\left(\max \left\{w+b r_{j}-\left(w+b r_{i}\right), 0\right\}\right)-\beta\left(\max \left\{w+b r_{i}-\left(w+b r_{j}\right), 0\right\}\right) \\
& =w+b r_{i}-\alpha\left(\max \left\{b\left(r_{j}-r_{i}\right), 0\right\}\right)-\beta\left(\max \left\{b\left(r_{i}-r_{j}\right), 0\right\}\right) \\
& , i \neq j \text { and } 0 \leq \beta<1,0 \leq \alpha .{ }^{5}
\end{aligned}
$$

\footnotetext{
${ }^{5}$ Agents are assumed to be inequality averse with respect to outcomes and do not take inputs (e.g. efforts) into account. We think this is a reasonable assumption since there is evidence that the vast majority of employees
} 
The special case of $\alpha=\beta=0$ pictures the utility of two purely self-interested agents who are only interested in their own wage. We assume $\beta<1$. This implies that agent $i$ cares more for his own utility than for the other agent's utility. In their seminal paper Fehr and Schmidt assume that $\alpha>\beta$. We do not need this assumption for our model. Dannenberg et al. (2007) provide experimental evidence that the opposite may be true in some circumstances.

Furthermore, we assume that the supervisor is interested in the accuracy of her statement and in the utilities of the agents. On the one hand, the supervisor suffers from $\operatorname{costs} v\left(r_{i}-p_{i}\right)^{2}$, if her report deviates from her observation. Hereby, $v>0$ measures the intensity of these costs from distorting evaluations. These costs may picture the potential cost of being fired if found out to have stated distorted evaluations. ${ }^{6}$ On the other hand, $S$ cares for the utilities of the agents. For example, she may want to avoid arguments with the agents and a negative working atmosphere in general (Bernardin \& Buckley 1981). The strength of this factor is represented by the parameter $\mu$. The supervisor's utility function is therefore given by

$$
\begin{array}{rlrl}
U_{S}\left(r_{i}, r_{j} \mid p_{i}, p_{j}\right) & =\mu\left(w+b r_{i}-\alpha\left(\max \left\{b\left(r_{j}-r_{i}\right), 0\right\}\right)-\beta\left(\max \left\{b\left(r_{i}-r_{j}\right), 0\right\}\right)\right. & \\
& \left.+w+b r_{j}-\alpha\left(\max \left\{b\left(r_{i}-r_{j}\right), 0\right\}\right)-\beta\left(\max \left\{b\left(r_{j}-r_{i}\right), 0\right\}\right)\right) & \\
& -v\left(r_{i}-p_{i}\right)^{2}-v\left(r_{j}-p_{j}\right)^{2}, \mu \geq 0 .
\end{array}
$$

Before deriving the optimal reports of the supervisor for inequality averse agents, we determine the performance appraisals for situations usually analyzed in more traditional economic models. The results can be taken as benchmarks compared to the results of our model:

1.) If the supervisor is merely self-oriented and does not care for her agents' utilities $(\mu=0)$, it is easy to show that she will report the true performances

$$
r_{i}=p_{i} \quad(i=1,2)
$$

by deriving her utility function with respect to the reports, because there would only costs but no benefits from deviating from the observations.

2.) If the supervisor cares for agents' utilities $(\mu>0)$ and the agents are not inequality averse but purely self-interested ( $\alpha=\beta=0)$, the supervisor maximizes $\mu\left(w+b r_{i}+w\right.$ $\left.+b r_{j}\right)-v\left(r_{i}-p_{i}\right)^{2}-v\left(r_{j}-p_{j}\right)^{2}$. Solving the first order condition for $r_{i}$ lead to the

consider themselves as top performers (Meyer 1975) so that differences in efforts will usually not be perceived equally across employees.

${ }^{6}$ Prendergast (2002) makes a similar assumption. 
optimal appraisals

$$
\tilde{r}_{i}=\frac{\mu b}{2 v}+p_{i} \quad(i=1,2) .
$$

In this case the supervisor overstates the agents' performances $(r>p)$. This result can be interpreted as the leniency bias. The size of this bias is increasing in the degree of the supervisor's preference for the agents' utilities and the monetary incentives of the agents. It is decreasing in the supervisor's costs of giving deviated reports. Each employee is upgraded to the same degree so that there is no centrality bias in this case.

In our model the supervisor also has to choose $r_{1}$ and $r_{2}$ - given her observations $p_{1}$ and $p_{2}-$ to maximize her utility by taking the inequality aversion of the agents into account. Note that the supervisor's utility function depends on her reports. Thus, we have to distinguish three different cases, because uneven reports lead to inequality between the agents.

$$
U_{S}= \begin{cases}\mu\left[2 w+b r_{i}-\beta b\left(r_{i}-r_{j}\right)+b r_{j}-\alpha b\left(r_{i}-r_{j}\right)\right]-v\left(r_{i}-p_{i}\right)^{2}-v\left(r_{j}-p_{j}\right)^{2} & \text { if } r_{i}>r_{j} \\ \mu\left[2 w+b r_{i}+b r_{j}\right]-v\left(r_{i}-p_{i}\right)^{2}-v\left(r_{j}-p_{j}\right)^{2} & \text { if } r_{i}=r_{j} \\ \mu\left[2 w+b r_{i}-\alpha b\left(r_{j}-r_{i}\right)+b r_{j}-\beta b\left(r_{j}-r_{i}\right)\right]-v\left(r_{i}-p_{i}\right)^{2}-v\left(r_{j}-p_{j}\right)^{2} & \text { if } r_{i}<r_{j} .\end{cases}
$$

The case of equal reports can also be integrated into the other parts of the supervisor's utility function so that we can write this as

$$
U_{S}= \begin{cases}\mu\left[2 w+b r_{i}-\beta b\left(r_{i}-r_{j}\right)+b r_{j}-\alpha b\left(r_{i}-r_{j}\right)\right]-v\left(r_{i}-p_{i}\right)^{2}-v\left(r_{j}-p_{j}\right)^{2} & \text { if } r_{i} \geq r_{j} \\ \mu\left[2 w+b r_{i}-\alpha b\left(r_{j}-r_{i}\right)+b r_{j}-\beta b\left(r_{j}-r_{i}\right)\right]-v\left(r_{i}-p_{i}\right)^{2}-v\left(r_{j}-p_{j}\right)^{2} & \text { if } r_{i} \leq r_{j} .\end{cases}
$$

Assume that $S$ observes $p_{i}>p_{j}$. She wants to maximize her utility and has to decide whether it is optimal to choose different or equal reports for the agents. To determine the optimal reports $r_{i}$ and $\mathrm{r}_{j}$, we first look at the first part of her utility function. If $S$ decides to choose a higher report for agent $i$ or equal reports for both agents, she maximizes this part of her utility function subject to the constraint $r_{i} \geq r_{j}$ which leads to

$$
L=\mu\left[2 w+b r_{i}-\beta b\left(r_{i}-r_{j}\right)+b r_{j}-\alpha b\left(r_{i}-r_{j}\right)\right]-v\left(r_{i}-p_{i}\right)^{2}-v\left(r_{j}-p_{j}\right)^{2}+\lambda\left(r_{i}-r_{j}\right) .
$$

The resulting Kuhn-Tucker-conditions are

$$
\begin{aligned}
& \mu b(1-\beta-\alpha)-2 v\left(r_{i}-p_{i}\right)+\lambda=0 \\
& \mu b(1+\beta+\alpha)-2 v\left(r_{j}-p_{j}\right)-\lambda=0
\end{aligned}
$$




$$
\lambda \geq 0, r_{i} \geq r_{j}, \lambda\left(r_{i}-r_{j}\right)=0
$$

From adding $\mathrm{K} 1$ and $\mathrm{K} 2$ we obtain

$$
\mu b / v+p_{i}+p_{j}=r_{i}+r_{j}
$$

Possible solutions include both different and equal reports. If $S$ chooses $r_{i}>r_{j}$, it follows from K3 that the Lagrangian multiplier $\lambda$ has to be zero. From K1 and K2 we obtain the evaluations for agent $i$ and $j$

$$
r_{i}^{\text {diff }}=\mu b(1-\alpha-\beta) / 2 v+p_{i} \text { and } r_{j}^{\text {diff }}=\mu b(1+\alpha+\beta) / 2 v+p_{j}{ }^{7}
$$

However, the first part of the supervisor's utility function is only valid for the range $r_{i}^{\text {diff }}>$ $r_{j}^{\text {diff }}$ so that

$$
p_{i}-p_{j}>\mu b(\alpha+\beta) / v
$$

has to hold. Since the term on the right side of inequality (1) is positive, the difference of the (observed) performances has to be sufficiently positive, too. Agent $i$ has to outperform his colleague to a sufficient amount to compensate for the creation of inequality if $S$ announces $r_{i}^{\text {diff }}>r_{j}{ }^{\text {diff }}$. Note that the right hand side of (1) is increasing in the inequality aversion parameters $\alpha$ and $\beta$. This is intuitive since it captures an agent's higher disutility when obtaining a report different from the one of his colleague. Furthermore, the right hand side is increasing in $\mu$ and in the report dependent wage component $b$ while decreasing in the supervisor's costs $v$ of deviating from the observed performances.

$S$ may choose $r_{i}=r_{j}$ in some cases, so that the agents cannot suffer from inequality. In this case we either have (I) $\lambda=0$ or (II) $\lambda>0$ (see K3).

(I) If $\lambda=0$ and $p_{i}-p_{j}=\mu b(\alpha+\beta) / v$ the reports solving all Kuhn-Tucker-conditions K1 to K3 are $r_{i}^{\text {even }}=\mu b(1-\alpha-\beta) / 2 v+p_{i} \quad$ and $r_{j}^{\text {even }}=\mu b(1+\alpha+\beta) / 2 v+p_{j}$, which are equivalent to

$$
r_{i}^{\text {even }}=r_{j}^{\text {even }}=r^{\text {even }}=\mu b / 2 v+\left(p_{i}+p_{j}\right) / 2 .^{8}
$$

\footnotetext{
${ }^{7}$ To capture the idea of different reports we will write $r_{i}^{\text {diff }}$ and $r_{j}^{\text {diff }}(i, j=1,2$ and $i \neq j)$.
} 
(II) If $S$ sets $r_{i}=r_{j}$ and we have $\lambda>0$, we also obtain $r_{i}^{\text {even }}=r_{j}^{\text {even }}=r^{\text {even }}=\mu b / 2 v+\left(p_{i}+p_{j}\right) / 2$ from K4. Subtracting K1 from K2 leads to the relevant condition for stating these reports: $p_{i}-p_{j}<\mu b(\alpha+\beta) / v$. If this condition is satisfied, the reports $r_{i}^{\text {even }}$ and $r_{j}^{\text {even }}$ solve the Kuhn-Tucker-conditions K1 to K3.

A similar reasoning can be applied to the maximization of the second part of the supervisor's utility function subject to the constraint $r_{i} \leq r_{j}{ }^{9}$ It is never optimal for the supervisor to give agent $j$ a better rating, while she observes that agent $i$ is the top performer (see Appendix A). If $S$ observes that agent $i$ 's performance is better than the performance of agent $j$, the only solution to the maximization problem of the second part of the utility function is to state equal reports $r_{i}^{\text {even }}=r_{j}^{\text {even }}=\mu b / 2 v+\left(p_{i}+p_{j}\right) / 2$. Since the first part of the supervisor's utility function corresponds to the second part of the utility function if reports are equal, different reports are only optimal if $p_{i}-p_{j}>\mu b(\alpha+\beta) / v$. Otherwise $S$ sets equal reports.

The derivation of the optimal reports when agent $j$ 's performance is at least as good as the performance of agent $i$ follows analogously. Our results are summarized in Proposition 1.

\section{Proposition 1:}

If both agents are inequality averse and the performance difference between the better agent $i$ and the worse agent $j$ is sufficiently large, i.e. $p_{i}-p_{j}>\mu b(\alpha+\beta) / v$, the supervisor optimally reports $\quad r_{i}^{\text {diff }}=\mu b(1-\alpha-\beta) / 2 v+p_{i} \quad$ and $r_{j}^{\text {diff }}=\mu b(1+\alpha+\beta) / 2 v+p_{j}$. If the performance difference is rather small, i.e., $-\mu b(\alpha+\beta) / \mathrm{v} \leq p_{i}-p_{j} \leq \mu b(\alpha+\beta) / \mathrm{v}$, the supervisor announces equal reports $r_{i}^{\text {even }}=r_{j}^{e v e n}=\mu b / 2 v+\left(p_{i}+p_{j}\right) / 2$.

It is easy to see that the supervisor's reports picture both the centrality bias and the leniency bias. If there are large performance differences between the agents, the supervisor tries to diminish the wage gap between the agents. This effect represents the centrality bias. The higher $\alpha$ and $\beta$, i.e. the more inequality averse the agents are, the larger is the range of equal reports and the larger the centrality bias.

\footnotetext{
${ }^{8}$ To capture the idea of equal reports we will write $r_{i}^{\text {even }}$ for $i=1,2$.

${ }^{9}$ The relevant Lagrange function and the resulting Kuhn-Tucker-conditions can be found in Appendix A.
} 
Given that $\alpha+\beta<1$ holds, both agents' performance ratings are higher than their observed performances, which represents the leniency bias. Otherwise, only the report for the agent with the lower observed performance is adjusted upwards. In this case the sum of the upward bias for the weaker employee and the downward bias for the top performer is always positive, so that the leniency bias always exists in sum. This distortion increases in the preference of the supervisor for the agents' utilities $(\mu)$ and in the report dependent wage component $(b)$. It is decreasing in her costs $v$ of deviating from the observed performances.

Inspecting the case of equal reports $r^{\text {even }}$, it is also straightforward that the supervisor generally rates the agent with the lower observed performance with leniency. However, similar to the case of different reports this does not always hold for the report for the agent with the higher observed performance. Again, the size of the leniency bias depends on the inequality aversion parameters $\alpha$ and $\beta$. Assume that $p_{i}>p_{j}$, then $r_{i}^{\text {even }}>p_{i}$ if $p_{i}-p_{j}<\mu b / v$. Proposition 1 states that the supervisor announces $r_{i}^{\text {even }}$ and $r_{j}^{\text {even }}$ if $-\mu b(\alpha+\beta) / v \leq p_{i}-p_{j} \leq \mu b(\alpha+\beta) / v$. Consequently the report for agent $i$ is only adjusted upwards if $\alpha+\beta<1$. In contrast the report for agent $i$ is lower than his observed performance, if $\alpha+\beta>1$ and $\mu b / v<p_{i}-p_{j} \leq \mu b(\alpha+\beta) / v$. However, the upward bias for the weaker agent always outweighs the possible downward bias for the better one.

If the agents' performances are exactly the same $\left(p_{i}=p_{j}=p\right)$, the supervisor reports $r_{i}^{\text {even }}=\mu b / 2 v+p$ (for $\left.i=1,2\right)$. This is the only case, in which the performance appraisals for inequality averse agents correspond to the reports for self-interested agents simply because there is no inequality. The leniency bias is also present in the case of purely self-interested agents, but the centrality bias cannot be explained.

\section{Favoritism}

In our basic model of section 2 we assume that the supervisor favors all agents. However, it may well be the case that a supervisor has only preferences for one of two subordinates (her favorite). For example, the supervisor knows one agent well and/or wants to reciprocate previous loyalty. In contrast, the other worker and the supervisor have no special relationship. 
For simplicity, we assume $\mu_{1}=\mu_{f}>0$ and $\mu_{2}=\mu_{n f}=0$ to investigate performance appraisals in such a situation. ${ }^{10}$ Therefore, the supervisor only favors agent 1 . Now optimal reports of the supervisor depend on the actual size of the inequality parameters of agent $1, \alpha$ and $\beta$, and on the size of the observed performance difference $p_{f}-p_{n f}$. Again, we have to distinguish between three cases.

First, if agent 1 is doing sufficiently better than agent 2 , i.e. $p_{f}-p_{n f}>\bar{B}=\mu_{f} b(2 \beta-1) / 2 v,{ }^{11}$ the supervisor reports $r_{f}{ }^{\text {diff }}=\mu_{f} b(1-\beta) / 2 v+p_{f}$ and $r_{n f}{ }^{\text {diff }}=\mu_{f} b \beta / 2 v+p_{n f}$. The favorite, agent 1 , obtains the higher rating, i.e. $r_{f}{ }^{\text {diff }}>r_{n f}{ }^{\text {diff }}$. These reports are similar to the reports in section 2. Since the supervisor now only cares for agent 1 , the upward bias of the reports is increasing in $\mu_{f}$. Although agent 2 is jealous of agent 1 , the supervisor neglects this fact. Thus, in contrast to $r_{1}^{\text {diff }}$ and $r_{2}^{\text {diff }}$ of section 2, the envy parameter $\alpha$ of agent 2 does not influence and align reports. Note that $\bar{B}$ will be negative if $\beta<1 / 2$. Therefore, the supervisor even upgrades agent 1 if his observed performance is (slightly) worse than agent 2's observed performance, if agent 1 does not feel much compassion with agent 2 when receiving a higher report. Both agents' ratings are higher than their observed performance which symbolizes the leniency bias. Although agent 1 is the favorite, he may be less upgraded than the other agent in some situations. This is a consequence of agent 1's compassion for agent 2 . Therefore, the supervisor wants to avoid a large difference in evaluations, which leads to the centrality bias again.

Second, if agents' performances differ only slightly, i.e. $\mu_{f} b(2 \beta-1) / 2 v=\bar{B} \geq p_{f}-p_{n f} \geq \underline{B}=-\mu_{f} b(2 \alpha+1) / 2 v,{ }^{12}$ the supervisor evaluates both agents equally and reports $r_{f}^{\text {even }}=r_{n f}^{\text {even }}=\mu_{f} b / 4 v+0.5\left(p_{f}+p_{n f}\right)$. This expression pictures the centrality bias. The range of this interval is increasing in the inequality aversion parameters of agent 1 (i.e. the higher $\alpha$ and $\beta$ ), is increasing in the degree the supervisor cares for his favorite (the higher $\mu_{f}$ ), is increasing in the report dependent wage component $b$ and is decreasing in the costs $v$ of deviating from the truth. A comparison of $r_{f}^{\text {even }}$ with $r^{\text {even }}$ of section 2 reveals that the first term $\mu_{f} b / 4 v$ is half of that of $r^{\text {even }}$. Thus, the first term is

\footnotetext{
${ }^{10}$ The index " $p$ " indicates that agent 1 is the favorite and the index " $n f$ 'indicates that agent 2 is not the favorite.

${ }^{11}$ A derivation of the threshold $\bar{B}$ can be found in Appendix B.

${ }^{12}$ We derive $\underline{B}$ in Appendix B.
} 
influenced by the number of agents the supervisor cares for. If $\beta<1 / 2$ so that $\bar{B}$ is negative, both agents receive the same ratings although agent 1's performance is worse than agent 2's performance. If $\beta>1 / 2$ ( $\bar{B}$ is positive), it is possible that reports are equal although agent 1 's observed performance is (slightly) better than the observed performance of agent 2. This is intuitive since a better rating would make agent 1 feel sorry for agent 2 and decrease his utility. Note that $r_{f}^{\text {even }}>p_{f}$. Therefore, agent 1's performance rating is affected by the leniency bias. In contrast, agent 2's rating is lower than his true performance if $-\mu_{f} b / 2 v>p_{f}-p_{n f} \geq \underline{B}$. Only if the observed performances are sufficiently close to each other, both ratings are biased upwards. Otherwise, only agent 1 profits from the evaluation. However, the upward bias for agent 1 always outweighs the possible downward bias of agent 2 .

Third, if $\quad p_{f}-p_{n f}<\underline{B}, \quad$ appraisals are $\quad \hat{r}_{f}^{\text {diff }}=\mu_{f} b(1+\alpha) / 2 v+p_{f} \quad$ and $\hat{r}_{n f}^{\text {diff }}=p_{n f}-\mu_{f} b \alpha / 2 v$. Now agent 1 obtains a lower performance assessment than agent 2 . Nevertheless, the assessment of agent 1 is higher than his observed performance (leniency bias) while the opposite is true for agent 2 . The bias is a consequence of agent 1 being jealous of agent 2's good performance. While the report of agent 1 is similar to that without favoritism of one particular agent in section 2, this does not hold for agent 2's report. In section 2 there are parameter ranges for $\alpha$ and $\beta$ so that the report for agent 2 is biased upwards. If agent 1 is the favorite and the supervisor does not care for agent 2 , this is not possible anymore. The considerations of this section can be summarized in proposition 2.

\section{Proposition 2:}

If the supervisor only cares for one agent, she reports

(i) equal appraisals $r_{f}^{\text {even }}=r_{n f}^{\text {even }}=\mu_{f} b / 4 v+0.5\left(p_{f}+p_{n f}\right)$ if $\bar{B} \geq p_{f}-p_{n f} \geq \underline{B}$ and (ii) different reports

(1) $r_{f}^{\text {diff }}=\mu_{f} b(1-\beta) / 2 v+p_{f} \quad$ and $\quad r_{n f}^{\text {diff }}=\mu_{f} b \beta / 2 v+p_{n f} \quad$ if $\quad p_{f}-p_{n f}>\bar{B}$ as well as

(2) $\hat{r}_{f}^{\text {diff }}=\mu_{f} b(1+\alpha) / 2 v+p_{f}$ and $\hat{r}_{n f}^{\text {diff }}=p_{n f}-\mu_{f} b \alpha / 2 v$ if $p_{f}-p_{n f}<\underline{B}$. 


\section{Endogenous Effort Choice of Agents}

In the last two sections we analysed the supervisor's performance appraisal decision when the agents' performances (and therefore efforts) were exogenously given. Now we want to investigate how the agents' incentives to exert effort and perform well are influenced by the biased reports of the supervisor if they anticipate her behavior. ${ }^{13}$ Thus, agents endogenously choose their efforts which determine their observed performance levels. We compare efforts in such a situation with a situation in which the supervisor does not care for the agents' utilities, i.e. a situation of unbiased reports.

The supervisor cannot observe the agents' efforts (and effort costs) but observes their performances $p_{1}$ and $p_{2} \cdot{ }^{14}$ On the basis of these observations she states her reports $r_{1}$ and $r_{2}$. For simplicity we assume that there are only two performance levels: a low performance level $p_{L}>0$ and a high performance level $p_{H}>0$ with $p_{H}-p_{L}>\mu b(\alpha+\beta) / v .^{15}$ Both agents simultaneously choose their efforts $e_{i} \in[0,1]$. When exerting effort $e_{i}$, an agent realizes $p_{H}$ with probability $e_{i}$ and $p_{L}$ with probability $1-e_{i}$ and suffers from effort costs $C\left(e_{i}\right)=c e_{i}^{2} / 2$. We assume

$$
c>b\left(p_{H}-p_{L}\right)(1+\alpha)>0 \text {. }
$$

This condition ensures that we only take interior solutions of optimal effort levels into consideration since the objective function is strictly concave. Moreover, we presume that supervisor and agents are mutually aware of their utility functions. Besides, all other assumptions from section 2 apply to this section as well.

Initially, we will explore effort choices for purely self-interested agents as a benchmark. We will compare the situation of an egoistic supervisor with the case that the supervisor cares for the two agents. Then, we will proceed by determining agents' effort choices for the case of agents’ inequality aversion.

\footnotetext{
${ }^{13}$ This is different from Prendergast (2002). An agent does not expect the supervisor's favoritism and therefore his incentives are not affected in his contribution.

${ }^{14}$ We assume that the participation constraint does not bind and thus both agents work for the firm.

${ }^{15}$ This assumption ensures that the supervisor chooses different reports for $i$ and $j$ in the case of deviating observations of performances.
} 


\subsection{Self-interested Agents}

First, we look at the behavior of purely self-interested agents and consider the case of a supervisor, who does not care for agents' utilities. She, therefore, always reports the agents' true performance levels $\left(r_{i}=p_{i}\right)$ so that reports are unbiased. An agent's expected utility (EU) is given by his fixed wage plus the expected bonus minus the effort costs:

$$
E U_{i, \text { unbiased,ego }}=w+e_{i} b p_{H}+\left(1-e_{i}\right) b p_{L}-c e_{i}^{2} / 2 .^{16}
$$

Solving the first order condition $\partial E U / \partial e_{i}=-c e_{i}+b\left(p_{H}-p_{L}\right)=0$ leads to the optimal effort of a self-interested (egoistic) agent:

$$
e_{i, \text { unbiased }, \text { ego }}^{*}=b\left(p_{H}-p_{L}\right) / c \equiv I / c \text {. }
$$

$I=b\left(p_{H}-p_{L}\right)$ represents the marginal return for a purely self-oriented agent from achieving the high performance in the case of unbiased reports. It is obvious that $e_{i, \text { unbiased,ego }}^{*}$ is decreasing in the effort costs parameter $c$. The more an agent receives from exerting effort (the higher the performance dependent wage component and the difference between the two performance levels) the higher is his effort level.

If the supervisor cares for the agents' utilities and therefore distorts her reports in the sense we have derived in section 2 , the expected utility of an agent is given by

$$
E U_{i, \text { biased,ego }}=w-\frac{c e_{i}^{2}}{2}+e_{i} b\left(\frac{\mu b}{2 v}+p_{H}\right)+\left(1-e_{i}\right) b\left(\frac{\mu b}{2 v}+p_{L}\right) .^{17}
$$

The first order condition $\partial E U / \partial e_{i}=-c e_{i}+b\left(p_{H}-p_{L}\right)=0$ leads to

$$
e_{i, \text { biased,ego }}^{*}=I / C \text {. }
$$

Hence, efforts are independent of the supervisor's preferences for egoistic agents. If the supervisor states biased reports, she upgrades her statements by $\mu b / 2 v$ independent of the realized performance level. We, therefore, can formulate

\footnotetext{
${ }^{16}$ The index "unbiased" indicates that the supervisor states the true performance while the index "ego" indicates the case of purely self-oriented agents.

${ }^{17}$ The index "biased" indicates that the supervisor does not report the true observed performances.
} 


\section{Proposition 3a:}

There is no incentive effect of report distortions for purely self-interested agents.

\subsection{Inequality Averse Agents and Unbiased Reports}

We now look at the behavior of inequality averse agents. First, we consider the case of unbiased reports with the supervisor reporting the agents' true performances $\left(r_{i}=p_{i}\right)$. Therefore, an agent's expected utility is given by ${ }^{18}$

$$
\begin{aligned}
& E U_{i, \text { unbiased,averse }}=w+e_{i} e_{j}\left(b p_{H}\right)+\left(1-e_{i}\right)\left(1-e_{j}\right)\left(b p_{L}\right) \\
& +\left(1-e_{i}\right) e_{j}\left(b p_{L}-\alpha b\left(p_{H}-p_{L}\right)\right)+e_{i}\left(1-e_{j}\right)\left(b p_{H}-\beta b\left(p_{H}-p_{L}\right)\right)-c e_{i}^{2} / 2 .
\end{aligned}
$$

If both agents realize the same low or high performance level, there are no inequality costs. However, agents suffer from inequality if they face different results. The first order condition $\partial E U / \partial e_{i}=-c e_{i}+b\left(p_{H}-p_{L}\right)-b \beta\left(p_{H}-p_{L}\right)+b e_{j} p_{H}(\alpha+\beta)-b e_{j} p_{L}(\alpha+\beta)=0$ gives us the optimal effort of agent $i$ given effort $e_{j}$ :

$$
e_{i}\left(e_{j}\right)=\left(I(1-\beta)+e_{j} I(\alpha+\beta)\right) / c \text {. }
$$

Intuitively, ambiguous effects are influencing the optimal effort here. Suppose that only agent $i$ exerts effort (which, of course, cannot be an equilibrium). Then agent $i$ is willing to exert the higher effort the more he can receive in the good state (when $p_{H}$ is realized). Having realized the good state while the other agent is worse off, makes agent $i$ feel compassion with his colleague and so his effort decreases in $\beta$. Let us call this negative effect the being ahead effect. If agent $j$ did not exert effort, agent $i$ could never be jealous of the other agent. Thus, his marginal return from achieving the high performance level is lower than the marginal return for a purely self-interested agent. If agent $j$ exerts effort, too, it is possible that agent $i$ has a lower compensation than agent $j$ ex post and is envious. Hence, agent $i$ wants to avoid this situation and his effort increases in $\alpha$. Furthermore, the negative influence of $\beta$ on agent i's effort is diminished but not cancelled out as long as there is still a positive probability that agent $j$ realizes $p_{L}$. We call this effect the partner effort effect. The higher this effect is the higher are the incentives to exert effort and to achieve the high performance level.

\footnotetext{
${ }^{18}$ The index "averse” indicates that both agents are inequality averse.
} 
In the symmetric Nash equilibrium $\left(e_{1, \text { unbiased,averse }}^{*}=e^{*}{ }_{2, \text { unbiased,averse }}\right)$ both agents exert effort

$$
e_{i, \text { unbiased,averse }}^{*}=\frac{(1-\beta) I}{c-(\alpha+\beta) I}
$$

Comparative statics show that $e_{i, \text { unbiased,averse }}^{*}$ is increasing in the performance dependent wage component $b$, in the performance difference $p_{H}-p_{L}$ and in the disadvantageous inequality parameter $\alpha .{ }^{19}$ An agent with a high $\alpha$ exerts high effort to decrease the probability of an unfavourable situation (i.e. a situation where he has only realized $p_{L}$, while the other agent has realized $p_{H}$ ). Moreover, effort decreases in $\beta$.

A comparison of inequality averse agents' efforts $\left(e_{i, \text { unbiased,averse }}^{*}\right)$ with the efforts of purely self-interested agents indicates that efforts are higher for inequality averse agents if

$\frac{(1-\beta) I}{c-(\alpha+\beta) I}>\frac{I}{c}$, which can be written as ${ }^{20}$

$$
c<I(\alpha+\beta) / \beta \quad \text { or } \quad I>\frac{c \beta}{\alpha+\beta}
$$

and leads to

\section{Proposition 3b:}

If the supervisor does not distort reports, inequality averse agents exert higher efforts in a symmetric Nash equilibrium than purely self-interested agents if and only if $c<I(\alpha+\beta) / \beta$.

Condition (3) shows that inequality averse agents exert higher efforts if effort costs are sufficiently low or the envy parameter is sufficiently high. Furthermore, condition (3) holds if the performance dependent wage component and the performance difference are sufficiently high. It illustrates that the positive effects on incentives which result from a positive effort of the other agent have to be quite high. If the partner effort effect dominates the negative being ahead effect, inequality averse agents exert higher efforts than purely self-interested agents, when reports are not distorted.

\footnotetext{
${ }^{19}$ See Appendix C.

${ }^{20}$ Thus, there exists an interval $[I(1+\alpha), I(\alpha+\beta) / \beta]$ for $c$ that guarantees interior solutions and higher efforts of inequality averse agents.
} 


\subsection{Inequality Averse Agents and Biased Reports}

Now, let us consider the case of biased reports, when the supervisor cares for the two inequality averse agents. Following Proposition 1, the supervisor will report $r_{i}^{\text {diff }}=\mu b(1-\alpha-\beta) / 2 v+p_{H}$ and $r_{j}^{\text {diff }}=\mu b(1+\alpha+\beta) / 2 v+p_{L}$ if she observes $p_{i}=p_{H}$ and $p_{j}=p_{L}$. If she observes $p_{H}\left(p_{L}\right)$ for both agents, she states $r_{i}^{\text {even }}=r_{j}^{\text {even }}=\mu b / 2 v+p_{H}$ $\left(r_{i}^{\text {even }}=r_{j}^{e v e n}=\mu b / 2 v+p_{L}\right)$. Thus, agent $i$ 's expected utility is given by

$$
\begin{aligned}
& E U_{i}=w-\frac{c e_{i}^{2}}{2}+e_{i} e_{j}\left(b\left(\frac{\mu b}{2 v}+p_{H}\right)\right)+\left(1-e_{i}\right)\left(1-e_{j}\right)\left(b\left(\frac{\mu b}{2 v}+p_{L}\right)\right) \\
& +\left(1-e_{i}\right) e_{j}\left(b\left(\frac{\mu b(1+\alpha+\beta)}{2 v}+p_{L}\right)-\alpha b\left(\frac{\mu b(1-\alpha-\beta)}{2 v}+p_{H}-\frac{\mu b(1+\alpha+\beta)}{2 v}-p_{L}\right)\right) \\
& +e_{i}\left(1-e_{j}\right)\left(b\left(\frac{\mu b(1-\alpha-\beta)}{2 v}+p_{H}\right)-\beta b\left(\frac{\mu b(1-\alpha-\beta)}{2 v}+p_{H}-\frac{\mu b(1+\alpha+\beta)}{2 v}-p_{L}\right)\right) .
\end{aligned}
$$

To determine the optimal efforts, we differentiate the agent's expected utility with respect to $e_{i}$ :

$$
\frac{\partial E U}{\partial e_{i}}=\frac{b}{2 v}\left(\begin{array}{l}
b \mu\left(-2 e_{j}(\alpha+\beta)^{2}+2 \beta^{2}+2 \alpha \beta-\alpha-\beta\right) \\
+2 v\left(\left(p_{H}-p_{L}\right)\left(1+e_{j}(\alpha+\beta)-\beta\right)\right.
\end{array}\right)-c e_{i}=0 .
$$

Solving for $e_{i}$ gives us the optimal effort of agent $i$ given effort $e_{j}$

$$
\begin{gathered}
e_{i}\left(e_{j}\right)=(b / 2 c v)\left(\begin{array}{l}
2 v(1-\beta)\left(p_{H}-p_{L}\right)+b \mu\left(2 \beta^{2}+2 \alpha \beta-\alpha-\beta\right) \\
+2 e_{j}\left(v\left(p_{H}-p_{L}\right)(\alpha+\beta)-\mu b(\alpha+\beta)^{2}\right)
\end{array}\right) \text { or } \\
e_{i}\left(e_{j}\right)=(1 / 2 c v)\left(2 v(1-\beta) I+\mu b^{2}\left(2 \beta^{2}+2 \alpha \beta-\alpha-\beta\right)+e_{j}\left(2 v(\alpha+\beta) I-2 \mu b^{2}(\alpha+\beta)^{2}\right)\right) .
\end{gathered}
$$

Now the effort choice depends on the costs of stating a distorted performance evaluation. Again, the effort of agent $i$ increases in the effort of agent $j$ which is characterized by the partner effort effect. ${ }^{21}$ However, although this effect is still positive it is lower than the effect if reports are not distorted. Given that agent $j$ realizes $p_{H}$ and agent $i$ only $p_{L}$, agent $i$ suffers less from being behind since the supervisor adjusts the performance appraisals and so reduces the difference in payoffs. The mitigation of the negative influence of $\beta$ through a positive

\footnotetext{
${ }^{21}$ This holds because we assume a sufficiently large performance difference $p_{H}-p_{L}>\mu b(\alpha+\beta) / v$.
} 
effort of the other agent is also decreased. Therefore, the partner effort effect is definitely diminished.

Furthermore, if the supervisor adjusts reports the negative being ahead effect is diminished if $\beta>1 / 2$. If agent $j$ has only realized $p_{L}$, his performance appraisal is increased by the supervisor and payoff differences are reduced. Since the distortion itself depends on the inequality parameters $\beta$ and $\alpha$, the magnitude of the reduction is also influenced by the size of $\alpha$. However, $\beta$ also decreases the report for agent $I$, which decreases incentives. Therefore, being ahead effect is only reduced if $\beta>1 / 2{ }^{22}$ If agent $i$ feels not much sympathy for his colleague (i.e. $\beta<1 / 2$ ), it even increases. This surprising result is independent of the sum of advantageous and disadvantageous inequality aversion $\alpha+\beta$. Although both agents are uprated if $\alpha+\beta<1$ and although the supervisor decreases inequality ex post, the change in reports is not strong enough to diminish the being ahead effect and ex ante even increases it if $\beta$ is small. Note that the supervisor increases her performance statement by $\mu b / 2 v$ in each possible situation independent of the realized performance level of the other agent. Ex ante incentives to exert effort are therefore not affected.

In a symmetric Nash equilibrium $\left(e_{1, \text { biased,averse }}^{*}=e_{2, \text { biased,averse }}^{*}\right)$ both agents exert effort

$$
e_{i, \text { biased, averse }}^{*}=\frac{2 v(1-\beta) I+b^{2} \mu(\alpha+\beta)(2 \beta-1)}{2 c v+2 \mu b^{2}(\alpha+\beta)^{2}-2 v(\alpha+\beta) I} .^{23}
$$

By comparing the efforts of inequality averse agents in the situations with and without biased reports, we can show that $e_{i, \text { biased,averse }}^{*}>e_{i, \text { unbiased,averse }}^{*}$ if and only if

$$
c(2 \beta-1)>I(\alpha+\beta)
$$

In this case the reduction of the being ahead effect dominates the reduction of the partner effort effect. Condition (4) demonstrates that incentives to exert effort with unbiased reports are always higher compared to a situation with biased reports if $\beta \leq 1 / 2$. If agents do not show compassion with each other $(\beta=0)$ but are jealous, biased reports always decrease incentives. If instead $\beta>1 / 2$ and there is a reduction of the negative being ahead effect, incentives can be higher when reports are skewed. This leads to

\footnotetext{
${ }^{22}$ Note that we subsume this incentive effect under the being ahead effect because it is relevant if agent $i$ has realized a higher performance level than agent $j$.

${ }^{23}$ Optimal efforts $e_{i, \text { biased,averse }}^{*}$ are smaller than one because of condition (2).

${ }^{24}$ A derivation can be found in Appendix C. Note that condition (4) is more restrictive than condition (2).
} 


\section{Proposition 3c:}

If both agents are inequality averse and $\beta \leq 1 / 2$, incentives to exert effort in a symmetric equilibrium are higher if the supervisor does not care for agents and reports are unbiased.

If both agents are inequality averse with $\beta>1 / 2$ and effort costs are rather high (i.e.c $>I(\alpha+\beta) /(2 \beta-1)$ ), incentives to exert effort in a symmetric equilibrium are higher with biased reports.

Intuitively, the effect of distorting reports on incentives is ambiguous. On the one hand, incentives to realize $p_{H}$ are higher the more an agent suffers from having a lower performance level than the other agent (the higher $\alpha$ ) in a situation with unbiased reports. This positive effect (working via the partner effort effect) is diminished since the supervisor's reports reduce the wage gap between both agents if different performance levels are realized. On the other hand, efforts decrease in the amount of compassion with the other agent, i.e. the higher $\beta$ in a situation with unbiased reports. This negative effect may also be diminished by the supervisor's reports.

Finally, we compare the efforts of inequality averse agents with the efforts of purely selfish agents when the supervisor cares for the agents' utilities. Since we concentrate on interior solutions, an interval $(L, K)$ with $L=I(1+\alpha)$ and $K=\frac{I\left(2 b \mu(\alpha+\beta)^{2}-2 v(\alpha+\beta)\left(p_{H}-p_{L}\right)\right)}{b \mu(\alpha+\beta)(2 \beta-1)-2 v \beta\left(p_{H}-p_{L}\right)}$ has to exist, which is derived in Appendix C. The effort cost parameter $c$ has to be above $L$, which describes the relevant condition for efforts to be smaller than one for this case (see condition 2). Then a comparison of efforts of inequality averse agents with the efforts of purely selfish agents shows that efforts of inequality averse agents are higher if $c<K$. However, the relevant interval $(L, K)$ does not always exist. Taking condition $1\left(p_{H}-p_{L}>\mu b(\alpha+\beta) / v\right)$ into account, it is obviously that we need a sufficiently large difference between the observed performance levels $p_{H}$ and $p_{L}$. Furthermore, the inequality parameter $\alpha$ has to be sufficiently high for a given $\beta$ to guarantee the existence of the interval. This leads to the following proposition: 


\section{Proposition 3d:}

If the performance difference $p_{H}-p_{L}$ and $\alpha$ are rather high for a given $\beta$, an interval $(L, K)$ for the effort cost parameter c exists, so that distorting reports lead to higher efforts of inequality averse agents compared to efforts of purely self-interested agents in a symmetric Nash equilibrium.

Two effects have to be taken into account. First, although the positive partner effort effect is diminished, it is still positive and therefore increases efforts of inequality averse agents compared to purely self-interested ones. Second, purely self-interested agents only take their own performance pay into account, when deciding about the amount of effort. In contrast, inequality averse agents also consider the income of the other agent and especially the situation, in which they themselves have realized $p_{H}$ while the other agent has only realized $p_{L}$. Without distorted reports, a higher $\beta$ decreases incentives, which characterizes the negative being ahead effect. This effect also exists with distorted reports. However, a higher $\beta$ (and $\alpha$ ) leads to a higher distortion of reports and therefore to less inequality, when reports are subject to the centrality and leniency bias. If $\beta$ is sufficiently high (i.e. $\beta>1 / 2$ ), the negative being ahead effect is diminished. Therefore, Proposition 3d demonstrates the conditions for the positive effect dominating the negative incentive effect.

Figure 2 summarizes our results for $\beta>1 / 2$. It pictures and compares the efforts of agents with different preferences (purely self-interested versus inequality averse) working with a supervisor who either states biased reports or the true performance of both agents. First, the efforts of self-oriented (egoistic) agents are lower than efforts of inequality averse agents without distorted reports if the positive effect for inequality averse agents (i.e. the partner effort effect) dominates the negative being ahead effect. This holds for the first two sections of Figure 2. Second, looking at the case that the supervisor cares for the agents, efforts of selforiented agents are lower than those of inequality averse ones if the (remaining) partner effort effect dominates the (remaining) being ahead effect. ${ }^{25}$ Third, we can compare the appraisals of inequality averse agents by both types of supervisors: Distorting reports increases incentives if the reduction of the partner effort effect is dominated by the reduction of the negative being ahead effect.

\footnotetext{
${ }^{25}$ Note that the partner effort effect is higher if reports are unbiased.
} 
Figure 2: Comparison of efforts of agents with different preferences dependent on the supervisor's preferences for $\beta>1 / 2$

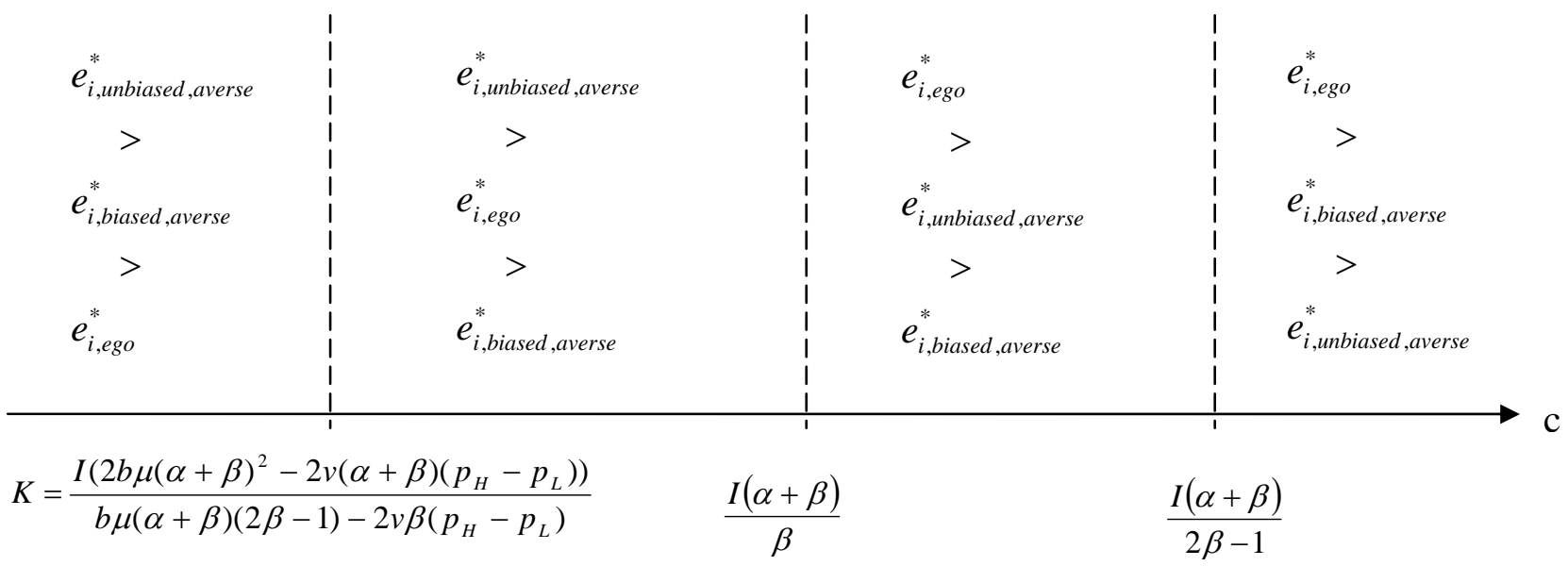

\section{Conclusion}

Many empirical studies have shown that subjective performance ratings of supervisors are subject to the centrality and leniency bias: Supervisors tend to differentiate only slightly between their subordinates so that ratings are compressed. Moreover, ratings are often skewed towards the top end of the rating scale. Our analysis offers a simple explanation for both biases: If supervisors care for the utility of their inequality averse subordinates, ratings may be distorted in both ways. The extent of the biases is influenced by the size of agents' inequality aversion and the difference in observed performances, for instance.

It is important to note that we are taking an ex ante perspective when analyzing incentives. Incentives are investigated before report contingent wages are paid. This is the usual perspective of principal agent models. Previous models with inequality averse agents have also chosen this approach. It is therefore neglected in these models that the outcome of performance appraisal may also affect future behavior of employees. A low rating, for instance, may discourage employees in the future and may therefore weaken incentives to exert effort. In contrast, it may also be possible that low rated employees show some kind of "now more than ever" behavior. In particular, if getting a low rating means being rated worse than the average, one reason for the extra motivation may be to persuade others of one's ability. Bol (2006) observes that biased performance appraisal outcomes influence future efforts. Her study is based on data of a financial service firm. She differentiates between the leniency and centrality bias and shows that lenient ratings positively affect performance improvement. In contrast, the centrality bias has a negative effect on future performance. 
From our ex ante point of view we show that lenient ratings do not affect incentives of purely self-interested agents in contrast to inequality averse agents. Incorporating this ex post perspective into theoretical models may be one interesting topic for future research. Taking additional wage costs for a principal into account, which could result from such ratings, could be another promising direction of research. The additional expected wage costs may outweigh positive incentive effects. Then the principal may not profit from engaging inequality averse agents compared to purely self-interested agents. 


\section{Appendix A}

If $p_{i}>p_{j}$ and $S$ would decide to choose a lower report for agent $i$ or equal reports for both agents, she maximizes the second part of her utility function subject to $r_{i} \leq r_{j}$. The relevant Lagrange function is

$$
L=\mu\left[2 w+b r_{i}-\beta b\left(r_{j}-r_{i}\right)+b r_{j}-\alpha b\left(r_{j}-r_{i}\right)\right]-v\left(r_{i}-p_{i}\right)^{2}-v\left(r_{j}-p_{j}\right)^{2}+\eta\left(\mathrm{r}_{\mathrm{j}}-r_{i}\right) .
$$

The resulting Kuhn-Tucker-conditions are

$$
\begin{aligned}
& \mu b(1+\beta+\alpha)-2 v\left(r_{i}-p_{i}\right)-\eta=0 \\
& \mu b(1-\beta-\alpha)-2 v\left(r_{j}-p_{j}\right)+\eta=0 \\
& \eta \geq 0, r_{j} \geq r_{i}, \eta\left(r_{j}-r_{i}\right)=0
\end{aligned}
$$

From adding K1' + K2' we obtain

$$
\mu b / v+p_{i}+p_{j}=r_{i}+r_{j} .
$$

We show by contradiction that $r_{j}>r_{i}$ cannot be a solution to this maximization problem. If $r_{j}>r_{i}$ holds, $\eta$ has to be zero and we obtain $r_{i}=\mu b(1+\beta+\alpha) / 2 v+p_{i}$ and $r_{j}=\mu b(1-\beta-\alpha) / 2 v+p_{j}$ from $\mathrm{K} 1$ ' and $\mathrm{K} 2$ '. However, $r_{j}>r_{i}$ only holds for $\mu b(1-\beta-\alpha) / 2 v+p_{j}>\mu b(1+\beta+\alpha) / 2 v+p_{i}$ or $p_{i}-p_{j}<-\mu b(\beta+\alpha) / v$. This leads to a contradiction since we assume $p_{i}>p_{j}$.

Similarly, $r_{j}=r_{i}$ and $\eta=0$ cannot be a solution. For $\eta=0$ we obtain $r_{i}=\mu b(1+\beta+\alpha) / 2 v+p_{i}$ and $r_{j}=\mu b(1-\beta-\alpha) / 2 v+p_{j}$ from K1' and K2'. But $r_{j}=r_{i}$ only holds for $p_{i}-p_{j}=-\mu b(\beta+\alpha) / v$ which again leads to a contradiction. The last possible solution is $r_{j}=r_{i}$ and $\eta>0$. Subtracting K2' from K1' leads to $2 \mu b(\alpha+\beta)-2 v\left(r_{i}-p_{i}\right)+2 v\left(r_{j}-p_{j}\right)=2 \eta>0 . \quad$ With $\quad r_{j}=r_{i} \quad$ we get $\eta=\mu b(\alpha+\beta)+v\left(p_{i}-p_{j}\right)$ and the relevant constraint is $p_{i}-p_{j}>-\mu b(\alpha+\beta) / v$. The resulting report for both agents is $r^{\text {even }}=\mu b / 2 v+\left(p_{i}+p_{j}\right) / 2$. Since we assume $p_{i}>p_{j}$, the only solution to the maximization problem of the second part of the supervisor's utility function which satisfies all Kuhn-Tucker-conditions is to state equal reports $r^{\text {even }}$ for $p_{i}-p_{j}>0$ 


\section{Appendix B}

\section{Derivation of the thresholds $\bar{B}$ and $\underline{B}$ and the optimal reports}

The supervisor's utility function can be described by

$$
U_{S}=\left\{\begin{array}{ll}
\mu_{f}\left[w+b r_{f}-\beta b\left(r_{f}-r_{n f}\right)\right]-v\left(r_{f}-p_{f}\right)^{2}-v\left(r_{n f}-p_{n f}\right)^{2} & \text { if } r_{f} \geq r_{n f} \\
\mu_{f}\left[w+b r_{f}-\alpha b\left(r_{n f}-r_{f}\right)\right]-v\left(r_{f}-p_{f}\right)^{2}-v\left(r_{n f}-p_{n f}\right)^{2} & \text { if } r_{f} \leq r_{n f}
\end{array} .\right.
$$

Assume $p_{f}-p_{n f}>0$. To determine the optimal reports $r_{f}>0$ and $r_{n f}>0, S$ decides whether to choose different or equal reports for both agents and then picks those reports that maximize her utility under this constraint. Again, we first look at the first part of her utility function. The relevant Lagrange function is

$$
L=\mu_{f}\left[w+b r_{f}-\beta b\left(r_{f}-r_{n f}\right)\right]-v\left(r_{f}-p_{f}\right)^{2}-v\left(r_{n f}-p_{n f}\right)^{2}+\lambda\left(\mathrm{r}_{\mathrm{f}}-r_{n f}\right) .
$$

The resulting Kuhn-Tucker-conditions are

$$
\begin{aligned}
& \mu_{f} b(1-\beta)-2 v\left(r_{f}-p_{f}\right)+\lambda=0 \\
& \mu_{f} b \beta-2 v\left(r_{n f}-p_{n f}\right)-\lambda=0 \\
& \lambda \geq 0, r_{f} \geq r_{n f}, \lambda\left(r_{f}-r_{n f}\right)=0
\end{aligned}
$$

By adding $\mathrm{K} 1$ and $\mathrm{K} 2$ we get

$$
\mu_{f} b / 2 v+p_{f}+p_{n f}=r_{f}+r_{n f} .
$$

There are two possible solutions: $r_{f}>r_{n f}$ or $r_{f}=r_{n f}$. If $S$ sets $r_{f}>r_{n f}$, it follows from K7 that $\lambda$ has to be zero. K5 and K6 lead to the reports $r_{f}^{\text {diff }}=\mu_{f} b(1-\beta) / 2 v+p_{f}$ and $r_{n f}{ }^{\text {diff }}=\mu_{f} b \beta / 2 v+p_{n f}$. However, the first part of $S$ 's utility function is only valid for the range $r_{f}>r_{n f}$. Thus if $p_{f}-p_{n f}>\mu_{f} b(2 \beta-1) / 2 v \equiv \bar{B}$, all conditions are satisfied and $r_{f}^{\text {diff }}$ and $r_{n f}{ }^{\text {diff }}$ solve the maximization problem.

In some cases, $S$ may set $r_{f}=r_{n f}$. In this case we either have (I) $\lambda=0$ or (II) $\lambda>0$ (see K7). (I) If $\lambda=0, r_{f}{ }^{\text {even }}=\mu_{f} b(1-\beta) / 2 v+p_{f}$ and $r_{n f}{ }^{\text {even }}=\mu_{f} b \beta / 2 v+p_{n f}$ will be the reports for the favorite and the other agent respectively (see K5 and K6). These reports solve all KuhnTucker-conditions and therefore are the solution to the maximization problem if $p_{f}-p_{n f}=\bar{B}$. These reports are equivalent to $r_{f}^{\text {even }}=r_{n f}{ }^{\text {even }}=\mu_{f} b / 4 v+0.5\left(p_{f}+p_{n f}\right)$. 
(II) If $\lambda>0$ and $S$ sets $r_{f}=r_{n f}$, we get $r_{f}^{\text {even }}=r_{n f}^{\text {even }}=\mu_{f} b / 4 v+0.5\left(p_{f}+p_{n f}\right)$ from K8. Subtracting K5 from K6 leads to the relevant condition for stating these reports: $p_{f}-p_{n f}<\mu_{f} b(2 \beta-1) / 2 v=\bar{B}$. Since we assumed $p_{f}-p_{n f}>0$, equal reports $r^{\text {even }}$ are the solution to the maximization problem of the first part of the utility function if the performance difference is rather low (i.e. $p_{f}-p_{n f} \leq \bar{B}$ ) and different reports are the solution if $p_{f}-p_{n f}>\bar{B}$

If $S$ decides to choose a lower report for her favorite or equal reports for both agents, she maximizes the second part of her utility function subject to the constraint $r_{n f} \geq r_{f}$. The relevant Lagrange function is

$$
L=\mu_{f}\left[w+b r_{f}-\alpha b\left(r_{n f}-r_{f}\right)\right]-v\left(r_{f}-p_{f}\right)^{2}-v\left(r_{n f}-p_{n f}\right)^{2}+\eta\left(\mathrm{r}_{\mathrm{nf}}-r_{f}\right) .
$$

The resulting Kuhn-Tucker-conditions are

$$
\begin{aligned}
& \mu_{f} b(1+\alpha)-2 v\left(r_{f}-p_{f}\right)-\eta=0 \\
& -\mu_{f} b \alpha-2 v\left(r_{n f}-p_{n f}\right)+\eta=0 \\
& \eta \geq 0, r_{n f} \geq r_{f}, \eta\left(r_{n f}-r_{f}\right)=0
\end{aligned}
$$

Adding K5' and K6' lead to

$$
\mu_{f} b / 2 v+p_{f}+p_{n f}=r_{f}+r_{n f} .
$$

Again, we show by contradiction that $r_{n f}>r_{f}$ cannot be a solution to this maximization problem. If $r_{n f}>r_{f}$ holds, $\eta$ has to be zero which leads to $\hat{r}_{f}^{\text {diff }}=\mu_{f} b(1+\alpha) / 2 v+p_{f}$ and $\hat{r}_{n f}^{\text {diff }}=p_{n f}-\mu_{f} b \alpha / 2 v \quad$ (see K5' and K6'). However, $r_{n f}>r_{f}$ only holds for $p_{f}-p_{n f}<-\mu_{f} b(2 \alpha+1) / 2 v \equiv \underline{B}$. This leads to a contradiction since we assume $p_{f}>p_{n f}$. Similarly $r_{n f}=r_{f}$ and $\eta=0$ cannot be a solution. With $\eta=0$ we obtain $r_{f}^{e v e n}=\mu_{f} b(1+\alpha) / 2 v+p_{f}$ and $r_{n f}^{e v e n}=p_{n f}-\mu_{f} b \alpha / 2 v$ from K5' and K6'. But $r_{n f}=r_{f}$ only holds for $p_{f}-p_{n f}=\underline{B}$ which leads to a contradiction since $\underline{B}<0$ and we assume $p_{f}>p_{n f}$.

The only possible solution is $r_{n f}=r_{f}$ and $\eta>0$. Subtracting K6' from K5' leads to $\mu_{f} b(1+2 \alpha)-2 v\left(r_{f}-p_{f}\right)+2 v\left(r_{n f}-p_{n f}\right)=2 \eta>0$. Taking $r_{n f}=r_{f}$ into account we get 
$\eta=\mu_{f} b(1+2 \alpha) / 2+v\left(p_{f}-p_{n f}\right)$. Equal reports $r^{\text {even }}=\mu_{f} b / 4 v+0.5\left(p_{f}+p_{n f}\right)$ solve all Kuhn-Tucker-conditions if $p_{f}-p_{n f}>-\mu_{f} b(2 \alpha+1) / 2 v \equiv \underline{B}$. Since we assume $p_{f}>p_{n f}$, the only solution to the maximization problem of the second part of the supervisor's utility function which satisfies all Kuhn-Tucker-conditions is to state equal reports. Since the first part of the supervisor's utility function corresponds to the second part of the utility function if reports are equal, different reports are only optimal if $p_{f}-p_{n f}>\bar{B}$. Otherwise $S$ sets equal reports.

The derivation of the optimal reports follows analogously, if the favorite's performance is at most as good as the performance of the other agent (i.e. $p_{f}-p_{n f} \leq 0$ ). Our results are summarized in Proposition 2. 


\section{Appendix C}

\section{Comparative statics:}

$e_{i, \text { unbiased, averse }}^{*}=\frac{(1-\beta) I}{c-(\alpha+\beta) I}$

$\frac{\partial e_{i, \text { unbiased }, \text { averse }}^{*}}{\partial \alpha}=\frac{I^{2}(1-\beta)}{(c-(\alpha+\beta) I)^{2}}>0$

$\frac{\partial e_{i, \text { unbiased, averse }}^{*}}{\partial \beta}=\frac{-I c+I^{2}(\alpha+1)}{(c-(\alpha+\beta) I)^{2}}<0 \quad$ (because of assumption (2))

$\frac{\partial e_{i, \text { unbiased,averse }}^{*}}{\partial I}=\frac{(1-\beta) c}{(c-(\alpha+\beta) I)^{2}}>0$

Comparison of $e_{i, \text { biased,averse }}^{*}$ and $e^{*}{ }_{i \text {,unbiased,averse }}$ :

$$
\begin{aligned}
& e_{i, \text { biased,averse }}^{*}>e_{i, \text { unbiased,averse }}^{*} \\
& \Leftrightarrow \frac{2 v(1-\beta) I+b^{2} \mu(\alpha+\beta)(2 \beta-1)}{2 c v+2 b^{2} \mu(\alpha+\beta)^{2}-2 v(\alpha+\beta) I}>\frac{(1-\beta) I}{c-(\alpha+\beta) I} \\
& \Leftrightarrow\left(2 v(1-\beta) I+b^{2} \mu(\alpha+\beta)(2 \beta-1)\right)(c-I(\alpha+\beta))>(1-\beta) I\left(2 c v+2 b^{2} \mu(\alpha+\beta)^{2}-2 v(\alpha+\beta) I\right) \\
& \Leftrightarrow 2 v c(1-\beta) I+b^{2} \mu c(\alpha+\beta)(2 \beta-1)-2 v I^{2}(\alpha+\beta)(1-\beta)-b^{2} \mu(\alpha+\beta)^{2}(2 \beta-1) I \\
& >2 v c(1-\beta) I+2 b^{2} \mu(1-\beta)(\alpha+\beta)^{2} I-2 v I^{2}(1-\beta)(\alpha+\beta) \\
& \Leftrightarrow b^{2} \mu c(\alpha+\beta)(2 \beta-1)-b^{2} \mu(\alpha+\beta)^{2}(2 \beta-1) I>2 b^{2} \mu(1-\beta)(\alpha+\beta)^{2} I \\
& \Leftrightarrow b^{2} \mu c(\alpha+\beta)(2 \beta-1)-b^{2} \mu(\alpha+\beta)^{2}(2 \beta-1) I>b^{2} \mu(2-2 \beta)(\alpha+\beta)^{2} I \\
& \Leftrightarrow b^{2} \mu c(\alpha+\beta)(2 \beta-1)>b^{2} \mu(2-2 \beta+2 \beta-1)(\alpha+\beta)^{2} I \\
& \Leftrightarrow b^{2} \mu c(\alpha+\beta)(2 \beta-1)>b^{2} \mu(\alpha+\beta)^{2} I \\
& \Leftrightarrow c(2 \beta-1)>I(\alpha+\beta)
\end{aligned}
$$




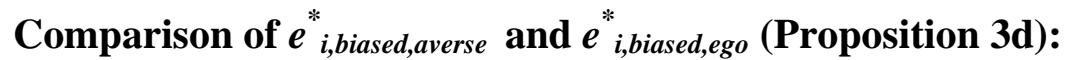

$$
\begin{aligned}
& e_{i, \text { biased, averse }}^{*}>e_{i, \text { biased, ego }}^{*} \\
& \Leftrightarrow \frac{2 v(1-\beta) I+b^{2} \mu(\alpha+\beta)(2 \beta-1)}{2 c v+2 b^{2} \mu(\alpha+\beta)^{2}-2 v(\alpha+\beta) I}>\frac{I}{c} \\
& \Leftrightarrow \frac{b\left(2 v(1-\beta)\left(p_{H}-p_{L}\right)+b \mu(\alpha+\beta)(2 \beta-1)\right)}{2 c v+2 b^{2} \mu(\alpha+\beta)^{2}-2 b v(\alpha+\beta)\left(p_{H}-p_{L}\right)}>\frac{b\left(p_{H}-p_{L}\right)}{c} \\
& \Leftrightarrow 2 c v(1-\beta)\left(p_{H}-p_{L}\right)+c b \mu(\alpha+\beta)(2 \beta-1)>\left(p_{H}-p_{L}\right) 2 c v+2 b^{2} \mu(\alpha+\beta)^{2}\left(p_{H}-p_{L}\right) \\
& \Leftrightarrow-2 c v \beta\left(p_{H}-p_{L}\right)+c b \mu(\alpha+\beta)(2 \beta-1)>2 b^{2} \mu(\alpha+\beta)^{2}\left(p_{H}-p_{L}\right)-2 b v(\alpha+\beta)\left(p_{H}-p_{L}\right)^{2} \\
& \Leftrightarrow c\left(b \mu(\alpha+\beta)(2 \beta-1)-2 v \beta\left(p_{H}-p_{L}\right)\right)>2 b^{2} \mu(\alpha+\beta)^{2}\left(p_{H}-p_{L}\right)-2 b v(\alpha+\beta)\left(p_{H}-p_{L}\right)^{2} \\
& \Leftrightarrow c<\frac{2 b \mu(\alpha+\beta)^{2} I-2 v(\alpha+\beta)\left(p_{H}-p_{L}\right) I}{\left(b \mu(\alpha+\beta)(2 \beta-1)-2 v \beta\left(p_{H}-p_{L}\right)\right)}
\end{aligned}
$$

Note, that denominator and numerator are both negative:

$2 b^{2} \mu(\alpha+\beta)^{2}\left(p_{H}-p_{L}\right)-2 b v(\alpha+\beta)\left(p_{H}-p_{L}\right)^{2}<0$ and

$b \mu(\alpha+\beta)(2 \beta-1)-2 v \beta\left(p_{H}-p_{L}\right)<0$, because we assume $p_{H}-p_{L}>\frac{\mu b(\alpha+\beta)}{v}$.

Thus, $c$ has to be in the interval

$$
\begin{aligned}
& \left(b\left(p_{H}-p_{L}\right)(1+\alpha), \frac{2 b^{2} \mu(\alpha+\beta)^{2}\left(p_{H}-p_{L}\right)-2 b v(\alpha+\beta)\left(p_{H}-p_{L}\right)^{2}}{b \mu(\alpha+\beta)(2 \beta-1)-2 v \beta\left(p_{H}-p_{L}\right)}\right)=(L, K) \text { or } \\
& \left(I(1+\alpha), \frac{I\left(2 b \mu(\alpha+\beta)^{2}-2 v(\alpha+\beta)\left(p_{H}-p_{L}\right)\right.}{b \mu(\alpha+\beta)(2 \beta-1)-2 v \beta\left(p_{H}-p_{L}\right)}\right)=(L, K)
\end{aligned}
$$

since we concentrate on interior solutions. Note that this condition only holds for sufficiently large performance differences and $\alpha$ for a given $\beta$. 


\section{References}

Bernardin, J. H., Buckley, R. M. (1981): Strategies in Rater Training. The Academy of Management Review 6, 205-212.

Biel, P. R. (2004): Inequity Aversion and Team Incentives. ELSE Discussion Paper, University College London.

Bol, J. C. (2005): Subjective Performance Evaluation. IESE Business School. University of Navarra.

Bol, J. C. (2006): The Determinants and Performance Effects of Supervisor Bias. IESE Business School. University of Navarra.

Bolton, G. E., Ockenfels, A. (2000): A Theory of Equity, Reciprocity, and Competition. American Economic Review 100, 166-193.

Bretz, R. D., Milkovich G. T., Read, W. (1992): The Current State of Performance Appraisal Research and Practice: Concerns, Directions, and Implications. Journal of Management 18, 312-352.

Cleveland, J. N., Murphy, K. R., Williams, R. E. (1989): Multiple Uses of Performance Appraisal: Prevalence and Correlates. Journal of Applied Psychology 74, 130-135.

Dannenberg, A., Riechmann, T., Sturm, B., Vogt, C. (2007): Inequity Aversion and Individual Behavior in Public Good Games: An Experimental Investigation. ZEW Discussion Paper No. 07-034.

Demougin, D., Fluet, C. (2003a): Group vs. Individual Performance Pay When Workers Are Envious. Cahier de recherche/Working Paper 03-18.

Demougin, D., Fluet, C. (2003b): Inequity Aversion in Tournaments. Scientific Series 2003s18.

Demougin, D., Fluet, C., Helm, C. (2005): Output and Wages with Inequality Averse Agents. Humboldt University Berlin. Mimeo.

Desiraju, R., Sappington, D. E. M. (2007): Equity and Adverse Selection. Journal of Economics and Management Strategy 16, 285-318.

Englmaier, F., Wambach, A. (2005): Optimal Incentive Contracts Under Inequity Aversion. IZA Discussion Paper No. 1643.

Fehr, E., Schmidt, K. M. (1999): A Theory of Fairness, Competition, and Cooperation. The Quarterly Journal of Economics 114, 817-868.

Ferris, G. R., Judge, T. A. (1991): Personnel/human Resources Management: A Political Influence Perspective. Journal of Management 17, 447-488.

Fox, S., Bizman, A., Herrman, E. (1983): The Halo Effect: Is it a Unitary Concept? Journal of Occupational Psychology 56, 289-296.

Grund, C., Sliwka, D. (2005): Envy and Compassion in Tournaments. Journal of Economics and Management Strategy 14, 187-207.

Holmström, B., Milgrom, P.R. (1991): Multitask Principal-Agent Analyses: Incentive Contracts, Asset Ownership, and Job Design. Journal of Law, Economics, and Organization 7, 24-52.

Itoh, H. (2004): Moral Hazard and Other-Regarding Preferences. Japanese Economic Review $55,18-45$. 
Ittner, C. D., Larcker, D. F., Meyer, M. W. (2003): Subjectivity and the Weighting of Performance Measures: Evidence from a Balanced Scorecard. The Accounting Review 78, 725-758.

Jawahar, I. M., Williams, C. R. (1997): Where All The Children are Above Average: The Performance Appraisal Purpose Effect. Personnel Psychology 50, 905-926.

Levy, P. E., Williams, J. R. (2004): The Social Context of Performance Appraisal: A Review and Framework for the Future. Journal of Management 30, 881-905.

Loewenstein, G. F., Thompson, L., Bazerman, M. H. (1989): Social Utility and Decision Making in Interpersonal Contexts. Journal of Personality and Social Psychology 57, 426-441.

MacLeod, W. B. (2003): Optimal Contracting with Subjective Evaluation. The American Economic Review 93(1), 216-240.

Mayer, B., Pfeiffer, T. (2004): Prinzipien der Anreizgestaltung bei Risikoaversion und sozialen Präferenzen. Zeitschrift für Betriebswirtschaft 74, 1047-1075.

Meyer, H. (1975): The Pay for Performance Dilemma. Organizational Dynamics 3, 39-50.

Milgrom, P.R., Roberts, J. (1988): An Economic Approach to Influence Activities in Organizations. American Journal of Sociology, Supplement, 94, S-154-S-179.

Murphy, K. J. (1992): Performance Measurement and Appraisal: Motivating Managers to Identify and Reward Performance. In: Bruns, W. J. (ed.): Performance Measurement, Evaluation, and Incentives, Boston, 37-62.

Murphy, K. R., Cleveland, J. N. (1991): Performance Appraisal: An Organizational Perspective, Bosten: Allyn and Bacon.

Murphy, K. R., Cleveland, J. N. (1995): Understanding Performance Appraisal. Thousand Oaks: Sage.

Neilson, W. S., Stowe, J. (2004): Incentive Pay for Other-Regarding Workers. Mimeo, Duke University.

Prendergast, C. (2002): Uncertainty and Incentives. Journal of Labor Economics 20, S115S137.

Prendergast, C., Topel, R. (1996): Favoritism in Organizations. Journal of Political Economy 104, 958-978.

Sliwka, D. (2007a): Loss Aversion and Bias in Subjective Performance Evaluations. Mimeo University of Cologne.

Sliwka, D. (2007b): Accuracy, Social Preferences and Bias in Subjective Performance Evaluation. Mimeo University of Cologne.

Varma, A., Denisi, A. S., Peters, L. H. (1996): Interpersonal Affect and Performance Appraisals: A Field Study. Personnel Psychology 49, 341-360.

von Siemens, F. (2005): Fairness, Adverse Selection, and Employment Contracts. University of Munich. Mimeo. 